\title{
Conservation Efforts for the Puerto Rican Mountain Coqui (Anura: Eleutherodactylidae: Eleutherodactylus portoricensis Schmidt, 1927): Reproductive Biology in Captivity ${ }^{1}$
}

\author{
Neftalí Ríos-López ${ }^{2,3}$, Eliacim Agosto-Torres², Rayza M. Hernández-Muñíz ${ }^{2}$, \\ Coralys Vicéns-López ${ }^{2}$, Ashley Bernardi-Salinas ${ }^{2}$, Waleska N. Tirado-Casillas ${ }^{2}$, and \\ Yvonne M. Flores-Rodríguez ${ }^{4}$
}

\begin{abstract}
Local and international herpetologists assert that the Puerto Rican Mountain Coqui, Eleutherodactylus portoricensis, has become locally extinct in all historic geographic distribution in the mountain forests of the Cordillera Central to western Puerto Rico, and that the species still experiences drastic population declines in the Sierra de Luquillo, eastern Puerto Rico. A species once though abundant throughout high elevation forests in Puerto Rico, these declines and local extirpations are difficult to explain, which resulted in the species listed vulnerable (local level) and endangered (IUCN) in need for immediate ex situ conservation efforts. We established the first ex situ conservation plan for E. portoricensis and herein document the first reproductive events of the species in captivity. We describe its amplexus, developmental period of clutches, oophagy, and use various elements provided in terrariums. We also discuss our trial and error events, and provide husbandry guidelines for this species that may expand our knowledge on keeping and breeding Eleutherodactylus frogs in need for ex situ conservation efforts.
\end{abstract}

Resumen: Herpetólogos locales e internacionales atestiguan la extinción local de poblaciones del Coquí de la Montaña, Eleutherodactylus portoricensis, en todo su rango geográfico histórico en los bosques de montaña a lo largo de la Cordillera Central de Puerto Rico hasta el extremo oeste de la misma, asi como la disminución poblacional en bosques de montaña en la Sierra de Luquillo al este de Puerto Rico. Al ser considerada una especie abundante en el pasado, la dismunución poblacional y extinción local de poblaciones que ha experimentado es muy dificil de explicar, lo que ha llevado a designarle como una especie Vulnerable a nivel local y en Peligro de Extinción (IUCN) con una necesidad imperiosa de esfuerzos de conservación ex situ. Por tal razón, hemos establecido el primer esfuerzo de conservación ex situ para esta especie y aquí documentamos su primer evento de reproducción exitosa bajo condiciones de cautiverio. Describimos su amplexo, periodo de desarrollo de sus camadas, oofagia y el uso de los elementos provistos en terrarios por los individuos en la colonia. También presentamos los fracasos y aciertos producto de medidas tomadas en beneficio del bienestar de los individuos en nuestra colonia y que pueden expandir nuestro conocimiento en materia del

\footnotetext{
${ }^{1}$ Submitted on July 16, 2015. Accepted on July 19, 2015. Last revisions received on July 21, 2015.

${ }^{2}$ Department of Biology, University of Puerto Rico-Humacao, Call Box 860, Humacao, Puerto Rico, 00792 USA.

${ }^{3}$ Corresponding author e-mail: neftali.rios@upr.edu,neftalirios@yahoo.edu

${ }^{4}$ HC-30, Box 35312, San Lorenzo, Puerto Rico, USA 00754. E-mail: bonnie_school@hotmail.com
}

DOI: 10.9784/LEB3(2)Rios.01

Electronically available on July 27, 2015. Mailed on July 25, 2015. 
cuido y mantenimiento de ranas de Eleutherodactylus que al igual que el Coquí de la Montaña puedan necesitar esfuerzos de conservación ex situ.

Key Words: amphibian husbandry, amplexus, ex situ conservation, hind-leg clasp, Mountain Coqui, oophagy.

The Puerto Rican Mountain Coqui (Eleutherodactylus portoricensis Schmidt, 1927) is a medium sized anuran (mean snout-vent length [SVL] 32. 2 mm males, $37.8 \mathrm{~mm}$ females: Joglar 1998) (Figure 1) that inhabits the ground and understory vegetation of rain forests in Puerto Rico. It is terrestrial in habits and reproduces by direct development (i.e. do not produce free-swimming larvae, and embryos undergo and complete development while in the egg to hatch as miniature replicas of adults). The geographic distribution includes the Sierra the Luquillo to the east, Sierra de Cayey to the southeast, and the Cordillera Central up to Maricao municipality to the eastern most Puerto Rico, and from $180 \mathrm{~m}$ above sea level to $1,189 \mathrm{~m}$ above sea level (Thomas 1966; Joglar 1998). The species shows male parental care, lays clutches between 16 and 20 eggs each, eggs are $5.1 \mathrm{~mm}$ in diameter on average (reviewed in Joglar 1998). An anecdotal account indicates that males of E. portoricensis may engage in filial oophagy if disturbed early during brooding (Stewart and Woolbright 1996).

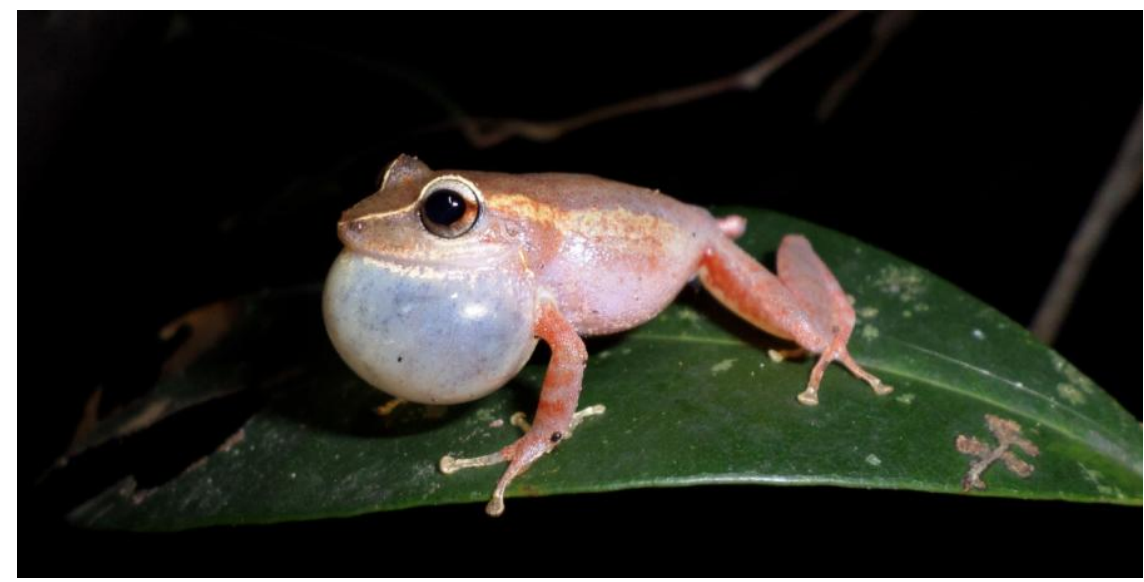

Figure 1. Calling male of Eleutherodactylus portoricensis.

Joglar (1998) asserts that Eleutherodactylus portoricensis was abundant in a distant past (prior to 1980s), but that the species was already rare between 1986 and 1998 in areas at El Yunque in the Sierra de Luquillo, Carite State Forest in the Sierra de Cayey, and Toro Negro (east) and Maricao (west) State Forests in the Cordillera Central. Several studies documented continued population declines of E. portoricensis at mid-elevation forests at El Yunque National 
Forest ( $\sim 660 \mathrm{~m}$ above sea level: Joglar and Burrowes 1996; Burrowes et al. 2004; Longo and Burrowes 2010). Burrowes and Joglar (2011) suggested that a synergistic interaction between an increased frequency of droughts and a fungal disease (chytridiomycosis from Batrachochytrium dendrobatidis Longcore, Pessier and D. K. Nichols, 1999 [Rhizophydiales: Batrachochytrium]) could be causal agents for observed patterns of declines at El Yunque National Forest. In the Sierra de Luquillo, the species was documented from elevations above 300 $\mathrm{m}$ at El Verde Research Station in 1978 (Beuchat et al. 1984), but it had disappeared from elevations up to $450 \mathrm{~m}$ by 1997 at El Verde Research Station (Woolbright 1997). While the species still thrives in the Sierra de Luquillo and in the Sierra de Cayey at elevations above 600-650 m (N. Ríos-López, pers. obs.), Barker et al. (2011) and Barker and Ríos-Franceschi (2014) have found not a single individual at the Cordillera Central mountain forests despite the presence of suitable forest habitat (surveyed localities from east to west within the Cordillera Central): Toro Negro State Forest (Ciales-Orocovis-Jayuya municipalities), Tres Picachos State Forest in Jayuya municipality, Monte Guilarte State Forest in Adjuntas municipality, and Maricao State Forest in Maricao municipality. The species has been listed Vulnerable by the Department of Natural and Environmental Resources of the Commonwealth of Puerto Rico (DNER 2004) and Endangered by the International Union for Conservation of Nature since 2004 (Angulo 2008).

Population declines and local extirpation of Eleutherodactylus portoricensis throughout its current and historic geographic distribution are difficult to explain, which called for immediate conservation measures (Burrowes and Joglar 2011; Johnson 2011a,b; Barker and Ríos-Franceschi 2014; AmphibianArk 2015). In situ conservation measures may include population studies in forest localities other than El Yunque to examine if observed patterns of population declines occur throughout Puerto Rico at large (Joglar 1998). According to recommendations and guidelines set by the IUCN Species Survival Commission in its Amphibian Conservation Action Plan (Gascon et al. 2007), ex situ conservation measures may require the establishment of a captivebreeding program in the species' range country with the ultimate goal to reintroduction to natural habitats once the original threats, if identified, have been overcome. The Amphibian Ark was created to carry out the ex situ components of the ACAP, and in 2011, recommended E. portoricensis for ex situ rescue during the 2011 Amphibian Ark Conservation Needs Assessment for Caribbean amphibians (a series of workshops held in Santo Domingo, Dominican Republic). In 2013, the Amphibian Ark awarded a seed grant to conduct an ex situ conservation plan for E. portoricensis at the University of Puerto Rico-Humacao Campus, Puerto Rico. Herein we document results from the ex situ component of our conservation plan for E. portoricensis, which also includes an in situ, field study on its population ecology being conducted in Cayey since mid 2013 (not presented herein). The ex situ component is aimed 
at producing enough individuals for reintroduction and the establishment of a self-sustained population in the wild. Specifically, we document several aspects of the species' reproductive biology in captivity including amplexus, filial oophagy, adult and juvenile husbandry techniques, and provide a baseline of challenges and troubleshooting as a reference for current and future ex situ conservation projects with other Eleutherodactylus frogs.

\section{Methods}

Specimen acquisition and laboratory settings. In December, 22, 2013, and January 18, 2014, we collected 23 adult individuals from Las Cruces (WGS $18.053^{\circ} \mathrm{N}, 66.122^{\circ} \mathrm{W} ; 807 \mathrm{~m}$ in elevation; Guayama municipality) and 24 individuals from Carite State Forest $\left(18.091^{\circ} \mathrm{N}, 66.032^{\circ} \mathrm{W}\right.$; $606 \mathrm{~m}$ in elevation; Patillas municipality), in the Sierra de Cayey, southeastern Puerto Rico. Between sites, we collected 19 adult males $(28.3-35.4 \mathrm{~mm}$, mean snout-vent length $31.4 \mathrm{~mm} \pm 1.9 \mathrm{~mm}, n=18)$, 10 females $(28.3-37.1 \mathrm{~mm}$, mean snout-vent length $32.2 \mathrm{~mm} \pm 2.9 \mathrm{~mm}, n=9)$, and 18 undetermined adults $(30.3-34.3 \mathrm{~mm}$, mean snout-vent-length $32.5 \mathrm{~mm} \pm 1.6 \mathrm{~mm}, n=5$ ). Adult males and females were identified by a combination of characters: in general, adult males are those found calling while adult females are those found gravid and lack a folded skin in the gular region, which is indicative of a vocal sac in males in present. All individuals were transported to the laboratory at the University of Puerto RicoHumacao Campus $\left(18.148^{\circ} \mathrm{N}, 65.838^{\circ} \mathrm{W} ; 28 \mathrm{~m}\right.$ in elevation; Humacao municipality, eastern Puerto Rico). This laboratory has two rooms, a small one used as breeding room, without openings to external daylight, and with dimensions approximately $2.4 \mathrm{~m}$ wide $\times 3.7 \mathrm{~m}$ long $\times 2.4$ high (Figure 2 ). The larger room is approximately three times as wide as the breeding room. Both rooms are equipped with an inverter air conditioner, plumbing, lighting, and electrical outlets with power connected also to an external emergency power plant.

Quarantine Period. All individuals underwent a quarantine period in the larger room before being kept in the breeding room. At their arrival, each individual is handled wearing vinyl gloves and using new gloves for each individual handled. The individuals are placed in a new deli cup with fresh Amphibian Ringers solution and a new paper towel, which are changed on a daily basis to avoid cross contamination. During the quarantine (which varied in duration-see Results), each individual was feed two or three $1.75 \mathrm{~cm}$ long crickets twice a week as needed. As a preventive measure, we prepared a $0.005 \%$ Itraconazole solution daily $(0.5 \mathrm{ml}$ of $10 \mathrm{mg} / \mathrm{ml}$ Itraconazole suspension to $100 \mathrm{ml}$ Ringers solution for amphibians) to bath each individual in this solution for 5 minutes once a day during a 10-day quarantine period following Pessier and Mendelson (2010). This protocol has also been used by the Abilene Zoo in Texas, USA, to treat the closely-related Red-eyed Coqui, E. antillensis Reinhardt and Lutken, 1863, against chytridiomycosis successfully (Animal 
Care Supervisor at the Abilene Zoo, T. Báez, pers. com.). Deli cups used for treatment were also new and changed on a daily basis for each individual treated, and each individual was rinsed with fresh Ringers solution before being placed in the quarantine deli cup.
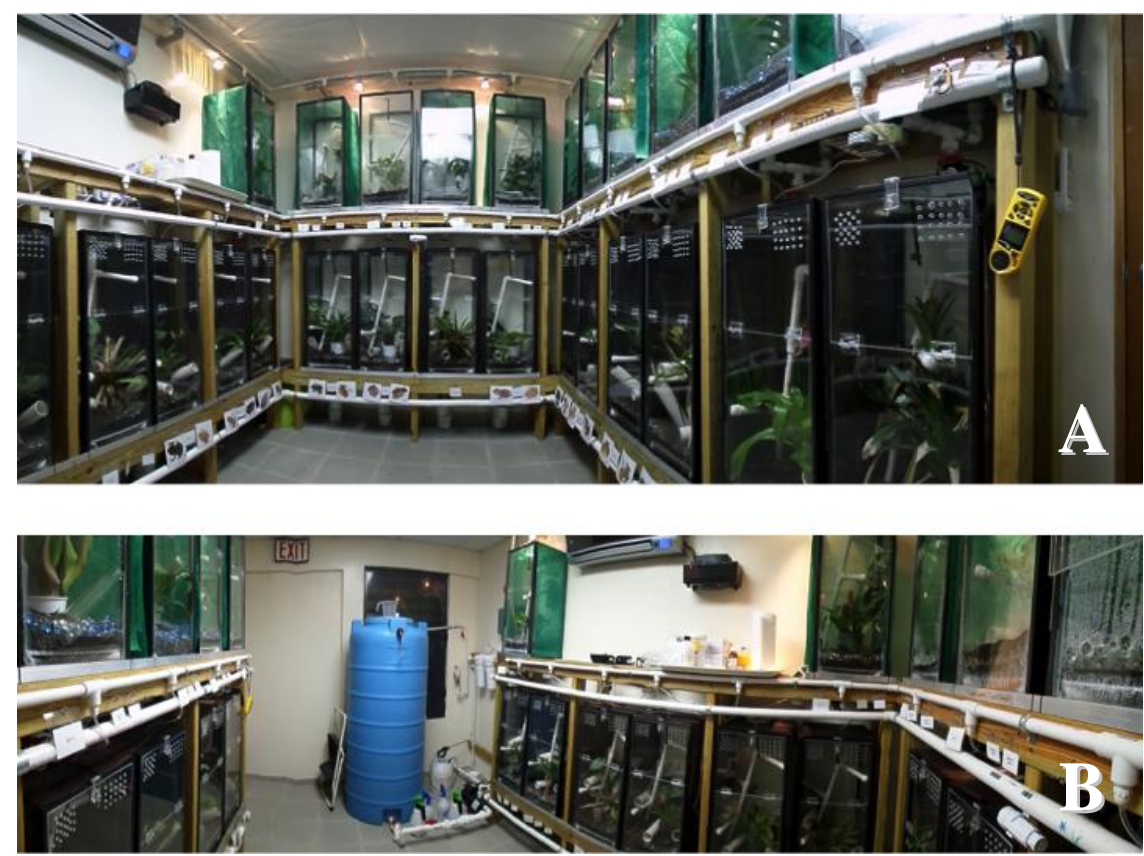

Figure 2. Front (A) and back (B) views of breeding room and captive facility terrariums for Eleutherodactylus portoricensis at the University of Puerto Rico-Humacao Campus. Shown in B is a blue colored, a 568-L collection tank of carbon- and sediment-filtered water used by the rain system.

Terrarium design. Initially, our terrarium design followed that described by Elinson et al. (1990) for the species' closely related Eleutherodactylus coqui Thomas, 1966 (Common Coqui), along with recommendations with several modifications. In the breeding room we built shelves that hold two rows of terrariums, each a $76.7 \times 31.7 \times 32.2 \mathrm{~cm} 75.7 \mathrm{~L}$ terrarium and that is set in an upright position to provide vertical space for treefrogs like E. portoricensis (Figure 2). Each terrarium is individually connected to a semi-automated rain system and a drainage outlet to reduce cross-contamination (Figure 3). We drilled two holes for drainage at the bottom of each terrarium and one smaller hole at the top for fitting a line for misting. We fitted a custom-made acrylic wall sealed to the bottom of the terrarium and a door that locks to the top of the terrarium that together covered the vertical extent of the terrarium from the bottom up. We measured the relative humidity in a terrarium and drilled small 
holes in two regions of its door to control for excess humidity inside the terrarium and to maintain the range of relative humidity within the range observed in the field (see next). Once this level was achieved, we drilled the same number of holes in the same locations in the terrarium door among terrariums. We added an artificial 'tree' made on PVC, hung a potted Philodendron plant, and added four $15 \mathrm{~cm}$ long sanitary PVC pipes $(2.5 \mathrm{~cm}$ in diameter) with a $15 \mathrm{~cm}$ long transparent fluorescent tube guard tightly secured inside the PVC tube. These tubes served as retreat and breeding sites for $E$. portoricensis and facilitate observations by sliding them out from the PVC pipe without disturbing the animal inside. We fitted a false bottom made of plastic egg crates covered with a plastic shade mesh, which in turn was covered with a $2.5 \mathrm{~cm}$ deep bed of pre-cleaned pebbles with a $2.5 \mathrm{~cm}$ deep layer of coconut husk as rehydration substrate. We choose coconut husk as it has been frequently recommended for its high retention capacity of humidity as an option for amphibian terrarium situations (R. Gagliardo, pers. comm.).

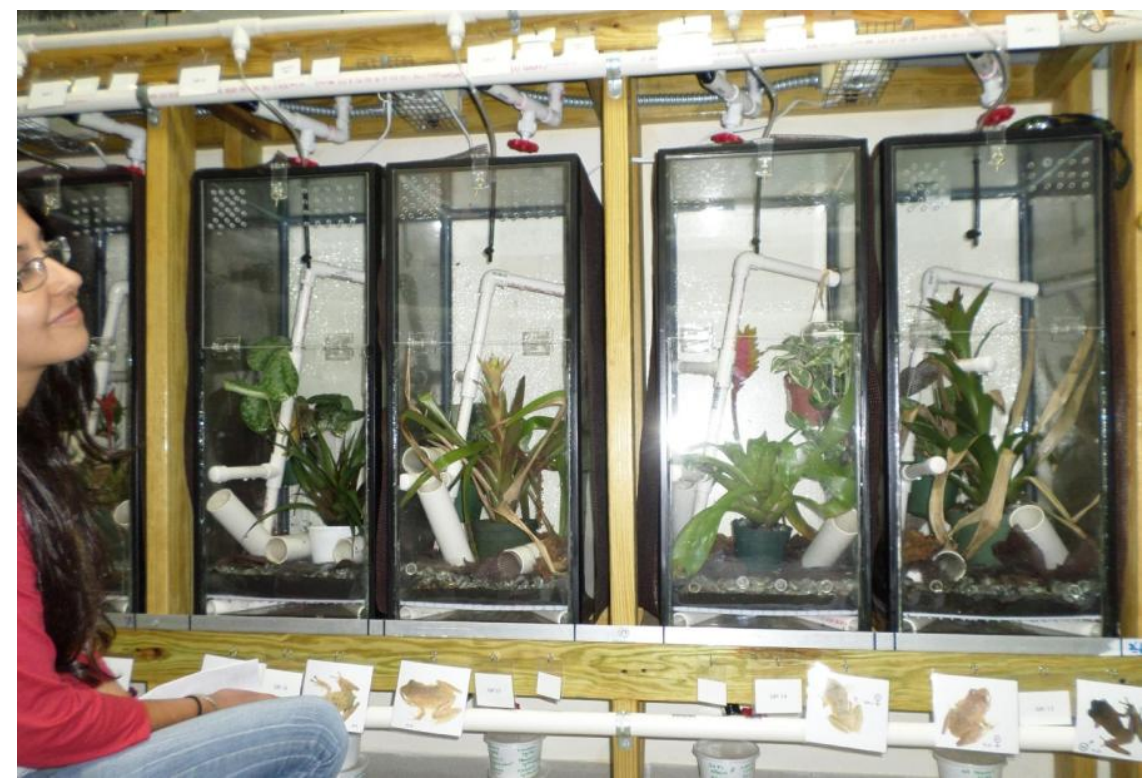

Figure 3. Detail of terrariums in the lower row of shelves in the breeding room as to April 22, 2014. In the picture, co-author R. M. Hernández.

Watering system, relative humidity, air temperature, and lighting cycles. We use a semi-automated rain system to mist the terrariums once a day for 1 minute and to mimic a heavy rain for 5 minutes once a week (on Fridays). All water used for the rain system is tap water run through two sequential charcoal and sediment filtration cartridges, and stored in a 568-L tank connected to a $1 / 2$ 
horse power water pump that distribute the water through $1.3-\mathrm{cm}$ diameter pipe line connected to a to each terrarium by the line of a mist nozzle (Figure 2). While relative humidity in the room is $63.1 \% \pm 13.0 \%$, this watering regime keeps relative humidity in terrariums at $85.1 \% \pm 8.9 \%$, which is close to the natural range in the species' locality during the rainy and warm season $(97.7 \% \pm$ 4.0\%, data collected between July 2013 and October 2014 at the forest collection site in Las Cruces). In addition, the air temperature in the room was held at $20.8^{\circ} \mathrm{C} \pm 1.1^{\circ} \mathrm{C}$ and at $20.5^{\circ} \mathrm{C} \pm 1.5^{\circ} \mathrm{C}$ in the terrariums, which is similar to the natural range in mean air temperature in the species' locality $\left(20.8^{\circ} \mathrm{C} \pm\right.$ $1.6^{\circ} \mathrm{C}$, data collected between July 2013 and October 2014 as above). Finally, the room is equipped with an automated lighting system connected to a timer, with fluorescent lights above the terrariums along with xenon halogen bulbs as source of UV. We have shifted the natural photoperiod gradually to facilitate observation of space use and breeding events, and lights are turned off at $1600 \mathrm{~h}$ and on at 0500 h every day.

Acoustic environmental enrichment. Males of Eleutherodactylus portoricensis call in small groups and in bouts in response to calls from nearby males (N. Ríos-López, pers. obs.), which suggests they can be induced to call more easily when provided with an external acoustic intra-specific stimuli. Therefore, we also installed a playback system using a $4^{\text {th }}$ generation Phone $^{\mathrm{TM}}{ }{ }$ (CApple, Inc.) plugged into an electric outlet, but the phone is connected through its audio jack output to two analog desktop computer speakers, which are connected to a timer on a different electric outlet. The phone is set for looping a $1.5 \mathrm{~h}$ recording of the anuran chorus in the Carite State Reserve during the species' peak calling hours (between $1930 \mathrm{~h}$ and $2100 \mathrm{~h}$; Drewry 1970), but the timer controls the on and off pattern for the speakers to generate a $7 \mathrm{~h}-3 \mathrm{~h}-2 \mathrm{~h}$ cycle of chorus-silence-chorus that mimicked the natural diel variation of the chorus in the species' anuran assemblage (see Drewry and Rand 1983). This recording system is synchronized to the lighting system as to turn on by the room's 'night time' and turn off by the room's 'day time', with the brief silence period in between the chorus cycle during the room's night time.

Diet and feeding regime. Adult individuals of Eleutherodactylus portoricensis are each fed three live house crickets (size approximately $1.9 \mathrm{~cm}$ long each) (Orthoptera; Gryllidae: Acheta domesticus Linnaeus, 1758) two times a week (usually on Mondays and Thursdays). Before feeding the frogs with crickets, each cricket is first fed commercially available TetraFin ${ }^{\circledR}$ flake food (Spectrum Brands, Inc., VA, USA, TechSupport@tetra-fish.com), and after approximately 5 minutes crickets are dusted with an approximately 3:1 mix of One A Day ${ }^{\circledR}$ Men's Health Formula (one tablet per feeding bout for the colony) (Bayer HealthCare LLC., NJ, USA) and Repti Calcium® ${ }^{\circledR}$ with Vitamin D3 (Zoo Med Laboratories, Inc., CA, USA, zoomed@zoomed.com). 


\section{Results}

Quarantine period, initial unexpected die-off, and trouble-shooting. By the end of January 2014 (one month after the first collection and two weeks after the second collection) we had an unexpected die-off in our colony, which was difficult to explain. First, we have been noticing that most individuals first collected developed a reddish rash in the distal ventral region and inner area of thighs, and became lethargic by the third day of treatment with the Itraconazole solution. We decided to stop the treatment immediately and kept the individuals in a deli cup as before for the duration of the quarantine period. By the end of the quarantine period, we took them out of the deli cups, rinsed them with Ringers solution, and placed a mating pair or a pair of undetermined individuals in a terrarium. We made our second collection of animals, kept them in deli cups, but this time during a 7-days quarantine period and without treating them for chytridiomycosis, and placed a mating pair or a pair of undetermined individuals in a terrarium as before. Second, several days after being moved into each terrarium, we started noticing that the humid coconut husk adhered to the skin of all individuals, and that they had difficulties getting it off from the skin even when watered by the rain system, but we did not think of this as problematic at first. During our routine check of the terrariums in January 28, 2014, we found 14 dead individuals (five females, three males, six undetermined) individuals from the first collection batch and seven individuals (two males, five undetermined) from the second collection batch. The finding was alarming considering that individuals from each collection batch were kept in pairs according to their place of origin, and were not mixed at this point in the project. We knew that coconut husk is highly absorbent too and suspected it may have affected the individual's ability to rehydrate (and might have acted in synergism with other potential, but unknown stressors in the terrariums).

On the same day we found this die-off, we took out each individual alive and kept them in new deli cups while we took out virtually all of the coconut husk from each terrarium, cleaned the terrarium with excess pre-filtered water, leaved the pebbles layer intact at the bottom, and added a $2.5 \mathrm{~cm}$ bed of $1-\mathrm{cm}$ diameter clear glass beads on top of the pebbles. On top of the layer of glass bed, we added several pieces of plastic shade mesh pre-cut into shapes of leaves, added sphagnum moss in a corner of the terrarium as a new rehydration substrate, and added a commercially available potted bromeliad (Guzmania sp.) as additional retreat and rehydration site. Each bromeliad was first rinsed during 2 minutes with $10 \%$ bleach solution and rinsed thoroughly with fresh filtered water for 5 minutes before being added to the terrarium. We watered the terrariums with the rain system for 10-15 minutes daily for the following three days before returning the rest of the individuals to the terrariums. After the change of bedding, the ceased of preventive treatment with Itraconazole solution (and else), and the new additions to the terrariums, we had only one dead 
individual, which died on May 1, 2014, and belonged to the December 2013 collection batch.

Adult growth, frequency of use of elements in terrarium, and reproductive biology. Between the initial collection date to July 13, 2015, adult males have grown on average $6.5 \mathrm{~mm} \pm 2.1 \mathrm{~mm}(3.9-10.1 \mathrm{~mm}$; mean SVL $37.9 \mathrm{~mm} \pm 1.3$ $\mathrm{mm}, n=10)$, with smaller males showing the largest increase in SVL $(r=-$ $0.8232, p=0.0017)$. Similarly, females have grown to $6.1 \mathrm{~mm} \pm 3.6 \mathrm{~mm}(2.7-$ $9.4 \mathrm{~mm}$; mean SVL $39.4 \mathrm{~mm} \pm 1.7 \mathrm{~mm}, n=4$ ), with smaller females showing the largest increase in SVL $(r=-0.9844, p=0.0078)$.

Use of space in the terrarium by adults varied between day and night hours, with the largest difference in detection of adults among substrate types occurring in the following types: PVC pipe, bedding of the potted Philodendron plant, Sphagnum moss, leaves of Philodendron plant, and glass walls of the terrarium. During the day, adults were most frequently found in the vicinity of the PVC pipe (30.9\%, mostly inside the pipe), and on the substrate of the potted plant (15.7\% versus $8.0 \%$ at night) and on the Sphagnum moss (8.3\% versus $4.0 \%$ at night). During the night, adults were most frequently found in the vicinity of the PVC pipe (36.1\%, mostly on top of the pipe), and on leaves of the potted plant (13.9\% versus $7.7 \%$ during the day) and on the surface of glass walls $(5.9 \%$ versus $2.2 \%$ during the day).

On April 29, 2014, we found a clutch inside a PVC pipe that was inclined in a corner of the terrarium and on top of the Sphagnum substrate (Figure 4). The male was found guarding the clutch, but he ate the clutch on May 2, 2014, without obvious reasons. On May 9, 2014, at 1039 h, we found a pair of Eleutherodactylus portoricensis in amplexus inside a PVC tube (Figure 5). The male was on top of the female and had grasped her in an axillary amplexus, while the female had engaged in a reverse hind leg clasp around the waist of the male during oviposition (Figure 5). Once the female finished laying eggs the male sat on top of the clutch for brooding. We did not interfere with the guarding male and the clutch, and hatching occurred on June 9, 2014 (see next). Including these clutches, we have found 20 clutches produced at the time this manuscript was submitted. These clutches were produced among seven mating pairs, with two males being mated with two females on separate occasions. The most recent clutch produced to this date was from June 29, 2015, deposited in an artificial bromeliad (the second clutch deposited in an artificial bromeliad; see below Challenges with live bromeliads for a description of artificial bromeliads) and that is still guarded by the male and developing normally. Precisely, the mating pair of this clutch has produced five clutches between January 2, 2015, and June 29, 2015, with a mean inter-clutch production frequency of 44.5 days \pm 5.9 days by the female. This pair has not predated a clutch to this date. 


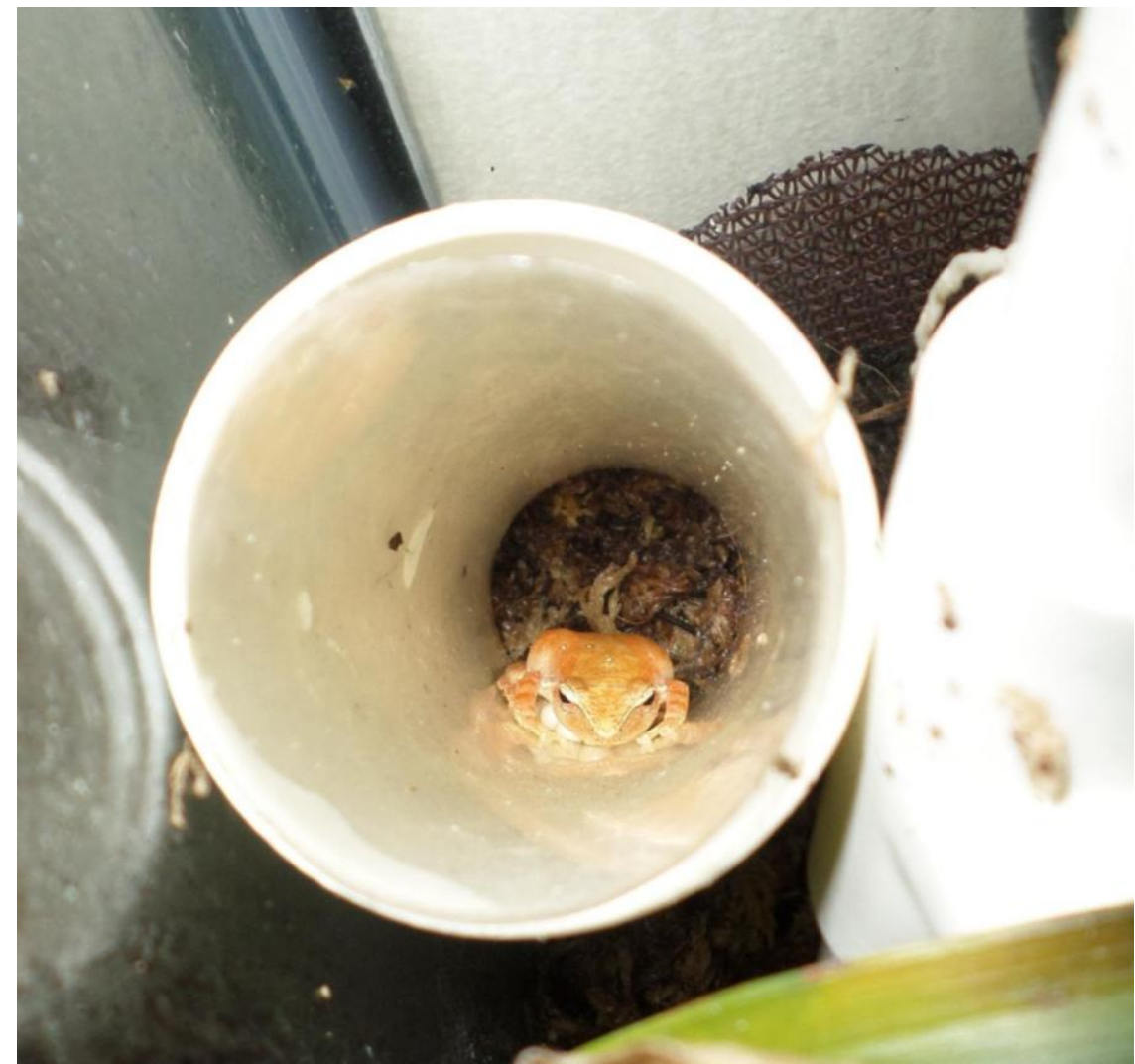

Figure 4. The first clutch of Eleutherodactylus portoricensis produced in our colony and found on April 29, 2014, along with a guarding male in its brooding position on top of the eggs. The arrow highlights two eggs visible beneath the male.

Not all clutches provided data for all descriptive statistics that follow as some clutches were abandoned, predated, were too young to disturbed, or are still developing at the time of this manuscript. On average, clutches consisted of 18.3 eggs \pm 5.6 eggs $(n=11)$ with a mean developmental period of 27.9 days \pm 5.6 days $(n=7)$. Percent fecundity is $95.1(n=10)$, with $57.9 \%$ hatching success (11/19), $10.5 \%$ abandonment (2/19), and $31.6 \%$ oophagy (6/19). In October 2014, we began removing the female of a pair with a recently laid clutch to an empty terrarium to minimize chances of oophagy, either by the female of by the male if disturbed by the female while guarding the clutch (in the field, a guarding male does eat his clutch if disturbed by an observer; $\mathrm{N}$ Ríos-López, pers. obs.). As a result, for the nine months that followed this removal practice we had one more incident of oophagy compared to the five 
incidents we had in the previous six months and since our first breeding event in the colony.

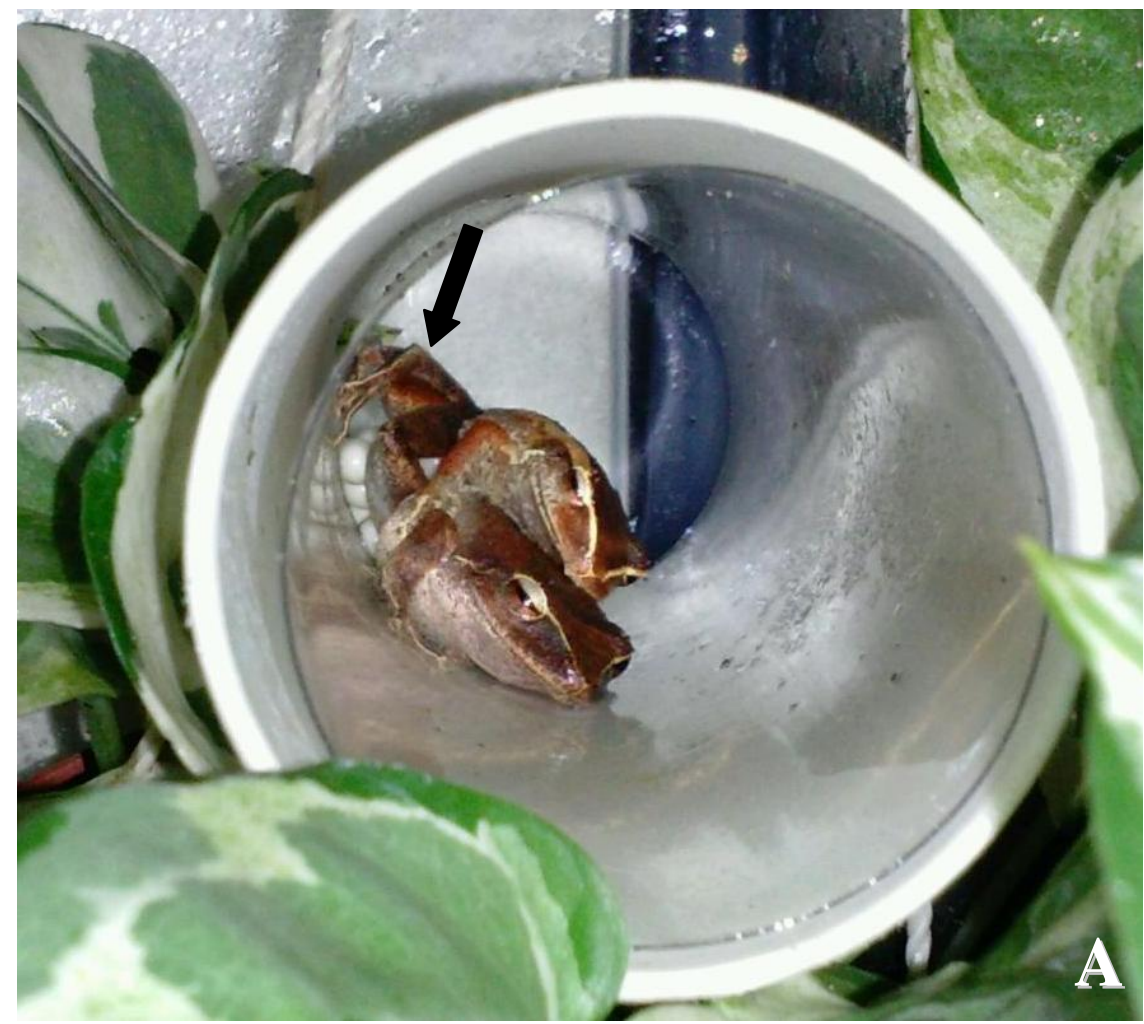

Figure 5A. A mating pair of Eleutherodactylus portoricensis with the male in an axillary amplexus on top of the female and the female engaged in a reverse hind-leg clasp around the waist of the male: on May 9, 2014, oviposition has begun on the transparent tube guard inside the PVC pipe on top of a potted Philodendron plant (which was hung on the PVC 'tree'; not shown). The arrow highlights the hind leg (HL) of the female clasping the male by his waist. 


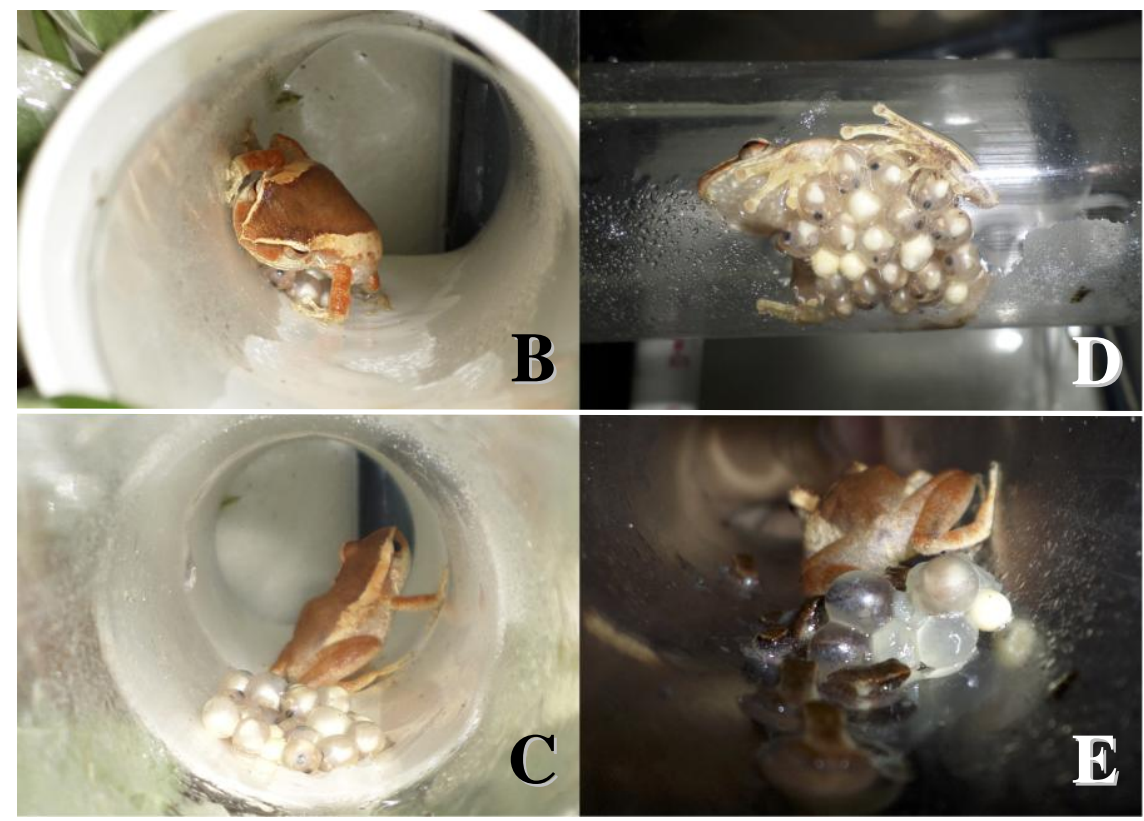

Figures 5B-E. In B-D, the guarding male on top of the clutch (B); behind the clutch in the tube guard $(\mathrm{C})$ that was slightly taken out to appreciate the clutch; and on top of the clutch viewed from beneath the tube guard that has been taken out from the PVC pipe to show the developing embryos in the eggs (D) (all pictures taken on June 1, 2014). In E, the clutch hatched on June 9, 2014, and hatchlings can be seen behind the guarding male.

Challenges with juvenile husbandry. Initially, we kept all recently hatched juveniles from each clutch in a clean 1-L plastic bottle, which has its bottom sparingly punctured for drainage, a $2.5 \mathrm{~cm}$ deep bed of commercially available pebbles for aquaria, and a nylon screen mesh on its cap for ventilation. We placed each miniterrarium in a shallow plastic dish filled with filtered water to approximately $1 \mathrm{~cm}$ deep to facilitate drainage and provide humidity to the terrarium. After approximately one week, we started feeding wingless fruit flies, directly as they come out from commercially available cultures, to hatchlings as recently hatched juveniles do not feed by their own while they retain their yolk reserved from between 5 and 7 days after being hatched. Many hatchlings died initially, however, presumably of starvation, as we frequently found regurgitated fruit flies in the terrariums.

We tried a different model of miniterrariums, which consisted of a 1-L glass terrarium that had $2.5 \mathrm{~cm}$ deep bed of a mix of vegetable charcoal and wood chips for potting plants, with a $2.5 \mathrm{~cm}$ deep layer of Sphagnum moss with a collembolan culture in it. This model has a heavily punctured lid for ventilation, the terrarium had no drainage, and we watered the terrarium to replace water 
loss to evaporation and to keep its water level to approximately $2 \mathrm{~cm}$ deep. We kept all hatchlings from a clutch together in the terrarium and we added fresh collembolans from cultures raised in our laboratory. We feed collembolans grounded rice every two to three days in our cultures, and added them to terrariums on a weekly basis to keep supply high for hatchlings. The collembolan culture in the terrariums did fine, and we then added winged fruit flies from commercially available cultures to each terrarium after hatchlings were in the terrarium for approximately one month. We continued to have high mortality in each batch of juveniles.

By the end of 2014, we moved hatchlings to 0.95-L deli cups, which had the bottom slightly punctured for drainage and to provide humidity to the terrarium, the cup was placed in shallow plastic dishes as before, it has a punctured lid for ventilation, and we added a $5 \mathrm{~cm}$ deep bed of Sphagnum moss only. We watered each miniterrarium with filtered water, we changed the diet of collembolan in our cultures to a 1:1 mix of TetraFin ${ }^{\circledR}$ flake food and grounded rice, and added collembolans ad libitum to each terrarium twice a week. We eliminated fruit flies from the diet of hatchlings, and kept hatchlings on a diet of collembolans only. As before, hatchlings took collembolans with ease until they were approximately three to four months old. Larger juveniles and these threeto-four month old juveniles were fed two to five pinhead-sized crickets, which were fed in turn freshly grounded TetraFin ${ }^{\circledR}$ flake food and were dusted with our 3:1 mix of multivitamins and calcium/D3 supplement before being added to juveniles. After this change in environmental conditions and diet, old juveniles and new hatchlings are doing fine so far. For the 11 clutches that hatched since the beginning of our project, we have changed the percent survivorship of hatchlings from $12.3( \pm 15.9, n=7)$ before these changes to $74.7( \pm 16.9, n=4)$ after these changes. Ninety-seven juveniles are now being raised on a diet based on multivitamin-feed and multivitamin-dusted collembolans, pin-sized crickets, and $1 / 2$ adult size crickets (approximately $1.7 \mathrm{~cm}$ long).

On average, one-month old hatchlings from the most recent clutches produced in our colony have a SVL of $8.5 \mathrm{~mm} \pm 0.2 \mathrm{~mm}(n=6)$ (Figure 6a). The age at which hatchlings reach adulthood is not known, but two of three juveniles that survived from a 9-egg clutch that hatched on September 12, 2014, and that are now 10-month old, have a SVL of $29.9 \mathrm{~mm}$ and $26.6 \mathrm{~mm}$, respectively (Figure 6b). The third juvenile, however, has a SVL of $13.0 \mathrm{~mm}$. The SVL of the largest juvenile from this batch falls within the lower range of SVL of individuals collected for our founder colony of breeders in December 2013 (the smaller individual being a male with a SVL of $28.3 \mathrm{~mm}$ at his arrival to the colony; it has now a SVL of $36.8 \mathrm{~mm}$ ). In contrast, nine juveniles from a clutch that hatched on June 9, 2014, have an average SVL of $16.2 \mathrm{~mm}( \pm 1.8$ $\mathrm{mm}$ ), with the largest individual having a SVL of $18.3 \mathrm{~mm}$. Two other juveniles from a clutch that hatched on August 11, 2014, have a SVL of $14.6 \mathrm{~mm}$ and 16.4 $\mathrm{mm}$, respectively. While the largest juvenile in our nursery may have reach an 
adult size in approximately 10 months, juveniles from clutches that hatched on June 2014 (13-month old juveniles) and August 2014 (11-month old juveniles) may reach the minimum adult size from individuals in our colony at approximately 22.5 months and 20 months, respectively.

Challenges with live bromeliads. Initially, we included live bromeliads (Guzmania sp.) from local commercially available suppliers for our terrariums. Most of these bromeliads died within two to three, and we suspected that they did not do well under conditions of low temperature and high humidity in our terrariums. We decided to add bromeliads (Guzmania sp.) collected from a near by locality where we collected Eleutherodactylus portoricensis in Cayey municipality, as we believed they were adapted to conditions of low temperature and high humidity in our terrariums. We cleaned and rinsed these bromeliads as before (see above), and placed them in pots with a mix of charcoal, wood chips, and Sphagnum moss as bedding. Most of these bromeliads also died within two to three months. In June 2014, we decided to build a functional artificial structure that mimicked a bromeliad microhabitat for our frogs, and replaced all natural bromeliads with these artificial bromeliads accordingly. Be September 2014 , we noted that our design of a bromeliad provided a humid retreat site for our frogs, and in January 26, 2015 we had our first clutch deposited and guarded by the male in an artificial bromeliad (Figure 7). As the date of submitting this manuscript our terrariums have only one potted Philodendron sp. plant with retreat and breeding sites mostly artificial (four PVC pipes with fluorescent guard tubes inside and one artificial bromeliad per terrarium). 


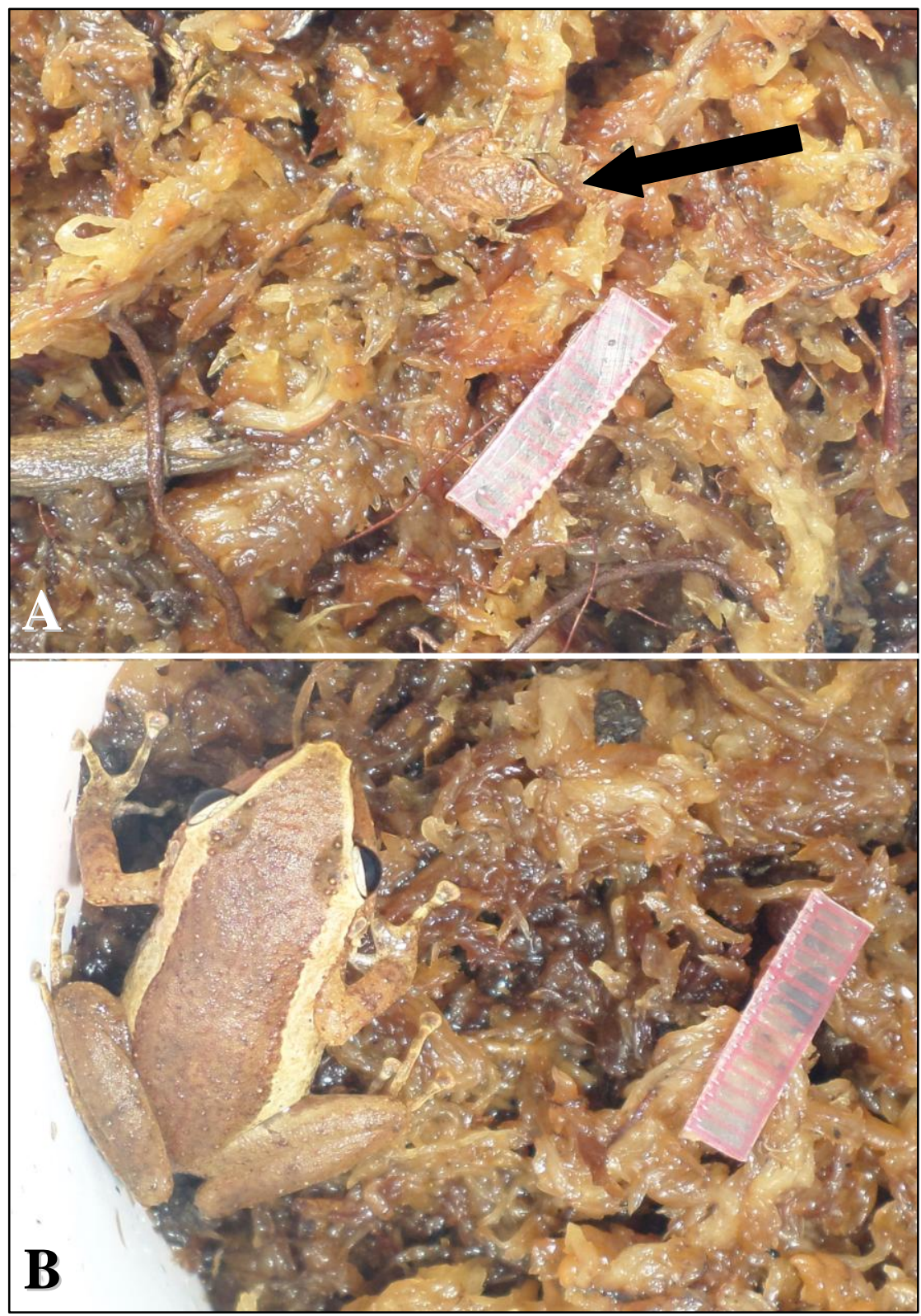

Figure 6. Differences in body size between juveniles: a one-month old juvenile (A) and 10 -month old juvenile (B; the fastest growing individual among juveniles so far). The arrow in A highlights the snout of the juvenile, and shown on both pictures is a $15-\mathrm{mm}$ long ruler for scale. 

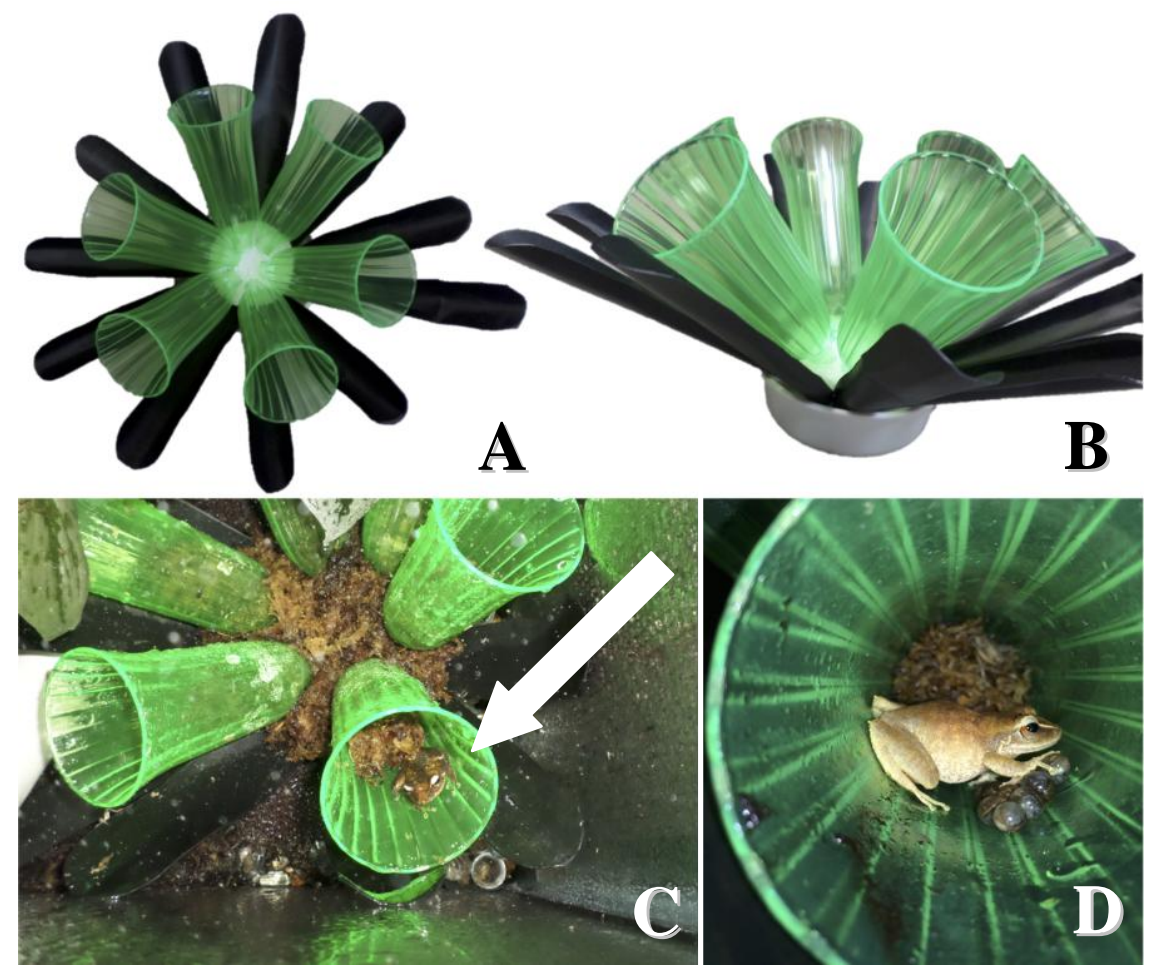

Figure 7. Top (A) and side (B) views of artificial bromeliads: bromeliads are constructed using plastic champagne cups that have the tip cut at an angle to facilitate their insertion into a 7.5- $\mathrm{cm}$ diameter foam disk forming a rosette. At the bottom of the base of each cup we drilled small holes for drainage because we do not want standing water in the terrariums for health reasons. Pre-cut plastic sheets, $15-\mathrm{cm}$ long by $2.5-\mathrm{cm}$ wide, are also inserted in the foam disk surrounding the outer border of the cup rosette to simulate 'leafs' for perching. The base of each cup is filled with Sphagnum moss to about $1.5 \mathrm{~cm}$ deep bed as rehydration substrate for frogs. The foam base of the finished bromeliad is securely inserted at the bottom of a $0.24-\mathrm{L}$ shallow deli cup that has small holes drilled at its base for drainage. The artificial bromeliad is placed on top of the bedding and adult Eleutherodactylus portoricensis readily adopted them as retreat (C) and breeding sites (D). In D, a male guarding its clutch inside on of the plastic cups (first clutch deposited in these bromeliads in January 26, 2015).

\section{Discussion, Comments, and Future Directions}

In a physiological study examining the response in jumping performance by Eleutherodactylus portoricensis under dehydration and thermal stress, Beuchat et al. (1984) showed that the species is very sensitive to high temperature $\left(>25^{\circ} \mathrm{C}\right)$, with individuals dying even a few days of exposure to $30^{\circ} \mathrm{C}$. These authors mentioned that the species breeds successfully at temperature as low as 
$15^{\circ} \mathrm{C}$ in the field, but that the species' rehydration capacity may be compromised at low temperature (between $15^{\circ} \mathrm{C}$ and $20^{\circ} \mathrm{C}$ ). The fact that $E$. portoricensis is sensitive to relatively small changes in temperature, suggests that the species rarely experiences a high variation in ambient temperature in its high-altitude forest habitat, which may explain the species' limited geographic distribution to high-elevation forests in Puerto Rico (Beuchat et al., 1984). We feel comfortable in having mimicked environmental conditions in the species' natural habitat, which included adequate diel variation in air temperature, watering and humidity level in terrariums, lighting cycle, and acoustic stimuli in the breeding room. These conditions, along with corrective measures for environmental enrichment (substrate and artifical elements added in terrariums) and proper feeding, allowed us to observed normal behavior and physiological responses related to reproduction like feeding, defecation, ovulation by females, calling by males, amplexus, clutch production, parental care, and hatching.

Amplexus in Eleutherodactylus portoricensis is similar to that in E. coqui described by Townsend and Stewart (1986) and Elinson et al. (1990). In E. coqui, the male engages into an axillary amplexus on top of the female while the female secures her mate by his hip using a reverse hind-leg clasp. Eleutherodactylus coqui has internal fertilization (Townsend et al. 1981) and this hind-leg clasp by the female results in close apposition of cloacae for effective sperm transfer in terrestrial situations (Townsend and Stewart 1986; Townsend et al. 1990). Presumably, E. portoricensis is the second species in which a reverse hind-leg clasp has been documented in the genus, which most likely suggest it also has internal fertilization.

Oophagy in Eleutherodactylus portoricensis is first quantified herein (approximately in 1/3 of clutches produced in captivity). We believe it occurred in response to disturbance, either by the presence of the female in the terrarium or the observer, as documented by Townsend et al. (1984) for E. coqui. For instance, we noticed that female feeds little when gravid, and once she lays a clutch of eggs she may be particularly starved. At that time, she represents a serious treat for the clutch being guarded. If successful, the female may displace the guarding male and devour the eggs. Likewise, the male may devour the eggs in response to her threat. Unfortunately, we have not seen a female or a male devouring eggs in our colony. However, we have seen a male that was guarding a recently laid clutch devouring all but two eggs after being disturbed by the observer while examining the male's breeding site (a rolled plastic flag used to mark a plot in our study areas in Cayey). Oophagy by a male has also being documented in the closely related E. coqui and the Cave-Dwelling Coqui, E. cooki Grant, 1932, under similar circumstances (Stewart and Woolbright 1996; Burrowes 2000; N. Ríos-López, pers. obs.), which may suggest this is a response that is more common that frequently though in these species.

The initial die-off of adults and hatchlings of Eleutherodactylus portoricensis were highly unexpected, considering that little is known about its 
biology and physiological requirements. However, we believe that changes made to our captive care and maintenance program, in response to such unforeseen challenges, were adequate for the successful breeding of the species. For example, we have provided proper elements for retreat, reproduction, rehydration, climbing, and bedding, which were all thoroughly rinsed with clean filtered water in advance. In addition, individuals were always handled with vinyl gloves to minimize the potential for cross-infections. We also feel comfortable in having mimicked environmental conditions and enrichment, including diel variation in lighting, watering, and acoustic stimuli in the breeding room. We now have individuals who are doing fine and look healthy for more than 17 months so far since their arrival to the colony (these were already adults when collected from the field), and have reduced mortality and increased hatching success. Consequently, our adaptive management effort in response to various challenges seem effective and allowed us to observe: normal feeding behavior; defecation; use of elements for rehydration (humid Sphagnum moss), retreat, and breeding; ovulation in females; calling by males; amplexus; brooding behavior; hatching; and raising juveniles close to adult size.

Data on the growth rate of individuals in the laboratory, although limited, suggest that juveniles may reach adult size (but not necessarily be reproductively mature) in approximately 20 to 22 months. Life expectancy of Eleutherodactylus portoricensis is unknown, but in the field, we expect that individuals spend more energy in feeding, food items may not be frequently accessible, and environmental stress may be greater for individuals in the field than in terrariums because of natural variation in temperature and humidity regimes. As a result, the period required for individuals to reach adulthood in the field may be longer that that under captive conditions. Rivero (1998) mentioned that longevity in E. coqui may reach five years, and estimates from Stewart and Woolbright (1996) for E. coqui in the field fell between four and six years. Consequently, we believe that individuals of E. portoricensis in our colony may now be at least around four years of age, and they might be close to the end of their reproductive fecundity.

Several species of Eleutherodactylus from Puerto Rico have been kept and bred in captivity for various purposes. For example, Elinson (1987) maintained breeding pairs of $E$. coqui that were allowed to mate and lay eggs naturally and collected their eggs for developmental studies; Michael (1995, 1996) kept mating pairs of E. coqui and E. cochranae (Whistling Coqui) for observations of their calling behavior, with successful breeding events in both species, but juveniles have not been raised to adults; likewise, Ríos-López (2007) kept and bred mating pairs of $E$. coqui and $E$. cochranae for observations on breeding behavior in captivity, but juveniles were not raised to adults; and Numazawa and Sengoku (2011) kept and bred mating pairs of E. monensis Meerwarth, 1901 (Mona Coqui) for observations of the species' breeding biology, but juveniles have not been raised to adults. In contrast, based on recommendations from the 
Amphibian Conservation Action Plan by Gascon et al. (2007), several species of Puerto Rican Eleutherodactylus have been kept and bred for ex situ conservation purposes. For example, Burrowes and Joglar (2011) highlighted captive breeding projects that have initiated with E. wightmanae Schmidt, 1920 (Melodious Coqui), E. richmondi Stejneger, 1904 (Richmond's Coqui), and E. locustus Schmidt, 1920 (Locust Coqui) in Central Florida Zoo, but while fertile eggs have been produced, juveniles have not been raised to adults; Stabile et al. (2014) initiated a captive breeding program with E. monensis, and while clutches and juveniles have been produced with most success, juveniles have not been raised to adults; Báez et al. from the Abilene Zoo, Texas, USA, are currently keeping and breeding mating pairs of E. antillensis with success, but juveniles have not been raised to adults (T. Báez, pers. com.). In summary, none of these initiatives, including current captive breeding programs being conducted in zoos and in response to the Amphibian Conservation Action Plan, are being conducted in the species' range country as desired. However, a philosophical and practical shift in conservation strategies is underway aimed at sponsoring and supporting ex situ conservation efforts in a species' range country and at institutions other than zoos (e.g., universities by way of Amphibian Ark's Seed grants). As such, this project with E. portoricensis represents the first such effort being conceptualized, developed, and conducted entirely in the species' range country and in a non-zoo institution.

While promising, we still need to improve many areas of our program, including sampling for diseases in new individuals intended for renewing our colony if necessary. Currently, we are unable to distinguish the proportion of deaths potentially attributed to major diseases, like chytridiomycosis and Ranavirus, from those attributed to stress brought in by external conditions in the terrariums (or both acting in synergism). According to Pessier and Mendelson (2010), reports of treatment-associated deaths are poorly documented, with a long list of challenges for eliminating infections, for example, of chytridiomycosis (and presumably of other high-profile diseases). These challenges include treatments not been consistently successful across species, and the urgent need for treatment trials (and combinations of treatments) among species to evaluate treatment efficacy, and tolerance and safety among species. These trials may require a large sample size of individuals and species. Other challenges include some treatments that are not tolerated by some species (medications can also be toxic to the animal), with treatment efficacy being probable species-specific (Pessier and Mendelson 2010). An underlying caveat is that we must be prepared to lose individuals in the process. We must decide on how much are we willing to lose in the attempt, and on what must be considered acceptable considering the fact that conservation resources are, in general, frequently limited. Such trials, however, are desperately needed (Pessier and Mendelson 2010), but the lack of information on what a normal background level is among Puerto Rican 
Eleutherodactylus, and how that level distinguishes from infection, virulence, and pathogenic levels with causal effects on species survival in the wild, preclude us address this issue in our captive breeding project with $E$. portoricensis at the moment.

In this project, we took corrective measures that seemed adequate for the benefit of our colony at first. These measures allowed us kept, bred, and raised few juveniles of Eleutherodactylus portoricensis to adult size, with the potential of having more of them replace, in the near future, the number of founders and those lost at the beginning without further collection from the wild. We will keep focusing on an expansion of our laboratory area as a nursery to accommodate a larger population of healthy, captive breed individuals. In addition, surplus of individuals being produced is considered for release in selected areas in the field. We emphasize the urgent need for field studies and treatment trials to address the ecology, persistence, and treatment of diseases like chytridiomycosis in E. portoricensis (and of other diseases in other Eleutherodactylus in Puerto Rico). In the meantime, however, the release of individuals of $E$. portoricensis in the wild must wait until we clearly understand the causes for its population decline and whether we have overcome those causes successfully.

\section{Acknowledgments}

We wish to thank three anonymous reviewers for their constructive and valuable suggestions that greatly improved this manuscript. We also thank the Amphibian Ark Seed Grant 2012-2013 for sponsoring this project; the Department of Natural and Environmental Resources of the Commonwealth of Puerto Rico for issuing permit number 2014-IC-099 (E) (R-VS-PVS15-SJ00710-24112014); the Institutional Animal Care and Use Committee (IACUC) at the University of Puerto Rico in Humacao for issuing the approved protocol; S. Miranda-Figueroa, G. G. Ma Cao, L. M. Sánchez-Delgado, and S. M. De León-Santiago for laboratory assistance; and laboratory technician H. Ramos and UPRH personnel for logistic support in facility design and construction.

\section{Literature Cited}

Amphibian Ark. 2015. Species prioritization: North America and Puerto Rico: Eleutherodactylus portoricensis. < http://aark.portal.isis.org>. Downloaded on 12 July 2015.

Angulo, A. 2008. Eleutherodactylus portoricensis. The IUCN Red List of Threatened Species. Version 2015.2. <www.iucnredlist.org>. Downloaded on 12 July 2015.

Barker, B. S, R. B. Waide, and J. A. Cook. 2011. Deep intra-island divergence of a montane forest endemic: phylogeography of the Puerto Rican frog Eleutherodactylus portoricensis (Anura: Eleutherdactylidae). Journal of Biogeography 38:2311-2325. http://dx.doi.org/10.1111/j.1365-2699.2011.02578.x

Barker, B. A. and A. Ríos-Franceschi. 2014. Population declines of Mountain Coqui (Eleutherodactylus portoricensis) in the Cordillera Central of Puerto Rico. Herpetological Conservation and Biology 9:578-589.

Beuchat, C.A., F.H. Pough, and M.M Stewart. 1984. Response to simultaneous dehydration and thermal stress in three species of Puerto Rican frogs. Journal of Comparative Physiology 154: 579-585.

Burrowes, P. A. 2000. Parental care and sexual selection in the Puerto Rican cave-dwelling frog, Eleutherodactylus cooki. Herpetologica 56:375-386.

Burrowes P. A. and R. L. Joglar. 2011. Puerto Rico: An island rich in amphibians subject to many threats. Froglog 96:16-17. 
Burrowes, P.A., R.L. Joglar, and D.E. Green. 2004. Potential causes for amphibian declines in Puerto Rico. Herpetologica 60:141-154. http://dx.doi.org/10.1655/03-50

Department of Natural and Environmental Resources. 2004. Reglamento para Regir las Especies Vulnerables y en Peligro de Extinción en el Estado Libre Asociado de Puerto Rico. State Department, Regulation Number 6766. San Juan, Puerto Rico, USA. 60 pp.

Drewry, G. E. 1970. Factors affecting activity of rain forest frog populations as measured by electrical recording of sound pressure levels. pp. E55-E68, Chapter E-4. In, Odum, H. T. and R. F. Pigeon (Editors). A Tropical Rain Forest: A Study of Irradiation and Ecology at El Verde, Puerto Rico. U. S. Atomic Energy Commission. Oak Ridge, Tennessee, USA. 1674 pp.

Drewry, G. E. and A. S. Rand. 1983. Characteristics of an acoustic community: Puerto Rican frogs of the genus Eleutherodactylus. Copeia 1983:941-953. http://dx.doi.org/10.2307/1445095

Elinson, R. P. 1987. Fertilization and aqueous development of the Puerto Rican terrestrial-breeding frog, Eleutherodactylus coqui. Journal of Morphology 193:217-224. http://dx.doi.org/10.1002/jmor.1051930208

Elinson, R. P., E. M. Del Pino, D. S. Townsend, F. C. Cuesta, and P. Eichhorn. 1990. A practical guide to the developmental biology of terrestrial-breeding frogs. Biological Bulletin 179:163177. http://dx.doi.org/10.2307/1541765

Gascon, C., J. P. Collins, R. D. Moore, D. R. Church, J. E. McKay, and J. R. Mendelson III (Editors). 2007. Amphibian Conservation Action Plan. IUCN/SSC Amphibian Specialist Group. Gland, Switzerland and Cambridge, UK. 64 pp.

Joglar, R. L. 1998. Los Coquíes de Puerto Rico: Su Historia Natural y Conservación. Editorial de la Universidad de Puerto Rico. San Juan, Puerto Rico, USA. 232 pp.

Joglar, R.L., and P.A. Burrowes. 1996. Declining amphibian populations in Puerto Rico. pp. 371-380. In, Powell, R. and R. W. Henderson (Editors). Contributions to West Indian Herpetology: A Tribute to Albert Schwartz. Contributions to Herpetology. Volume 12. Society for the Study of Amphibians and Reptiles. Ithaca, New York, USA. 457 pp.

Johnson, K. 2011a. Amphibian Conservation Needs Assessment Workshop for the Caribbean. Froglog 96:12-13.

Johnson, K. 2011b. Amphibian Conservation Needs Assessment Workshop for the Caribbean Region. IRCF Reptiles \& Amphibians (18):145-147.

Longo, A.V. P.A. Burrowes. 2010. Persistence with chytridiomycosis does not assure survival of direct-developing frogs. EcoHealth 7:185-195. http://dx.doi.org/10.1007/s10393-010-0327-9

Michael, S. F. 1995. Vocalization and diurnal retreat defense in the Puerto Rican frog Eleutherodactylus cochranae. Journal of Herpetology 31:453-456. http://dx.doi.org/10.2307/1565681

Michael, S. F. 1996. Courtship calls of three species of Eleutherodactylus from Puerto Rico (Anura: Leptodactylidae). Herpetologica 52:116-120.

Numazawa, M. and S. Sengoku. 2011. Observations on the reproduction in captivity of the Mona Coqui Eleutherodactylus monensis (Anura: Leptodactylidae) from Puerto Rico. Current Herpetology 30:181-186. http://dx.doi.org/10.5358/hsj.30.181

Pessier, A. P. and J. R. Mendelson (Editors). 2010. A Manual for Control of Infectious Diseases in Amphibian Survival Assurance Colonies and Reintroduction Programs. IUCN/SSC Conservation Breeding Specialist Group. Apple Valley, Minnesota, USA. 229 pp.

Ríos-López, N. 2007. The Structuring of Herpetofaunal Assemblages in Human-Altered Coastal Ecosystems. Dissertation thesis, University of Puerto Rico, Río Piedras Campus, San Juan, Puerto Rico, USA. 234 pp.

Rivero, J. A. 1998. The Amphibians and Reptiles of Puerto Rico. Second Edition. Editorial de la Universidad de Puerto Rico, San Juan, Puerto Rico, USA. 510 pp.

Stabile, J. L., L. A. Santiago, and R. L. Joglar. 2014. Reproductive biology of the Mona Coqui (Eleutherodactylus monensis) in captivity. Herpetological Review 45:248-250.

Stewart, M. M. and L. L. Woolbright. 1996. Amphibians. pp. 273-320. In, D. P. Reagan and R. W. Waide (Editors). The Food Web of a Tropical Rain Forest. University of Chicago Press. Chicago, Illinois, USA. 616 pp. 
Thomas, R. 1966. New species of Antilean Eleutherodactylus. Quarterly Journal of the Florida Academy of Sciences 28:375-391.

Townsend, D. S. and M. M. Stewart. 1986. Courtship and mating behavior of a Puerto Rican frog, Eleutherodactylus coqui. Herpetologica 42:165-170.

Townsend, D. S., M. M. Stewart, and F. H. Pough. 1984. Male parental care and its adaptive significance in a Neotropical frog. Animal Behaviour 32:421-431. http://dx.doi.org/10.1016/S0003-3472(84)80278-X

Townsend, D. S., M. M. Stewart, F. H. Pough and P. Brussard. 1981. Internal fertilization in a oviparous frog. Science 212:469-471. http://dx.doi.org/10.1126/science.6894203

Townsend, D. S., R. J. Wassersug, V. A. King, and G. C. B. Elder. 1990. Sexual dimorphism in the hindlimb of Eleutherodactylus coqui: does behavior predict morphology? The Journal of Experimental Zoology 255:350-354.

Woolbright, L. L. 1997. Local extinctions of anuran amphibians in the Luquillo Experimental Forest of northeastern Puerto Rico. Journal of Herpetology 31:572-576. http://dx.doi.org/10.2307/1565612 